
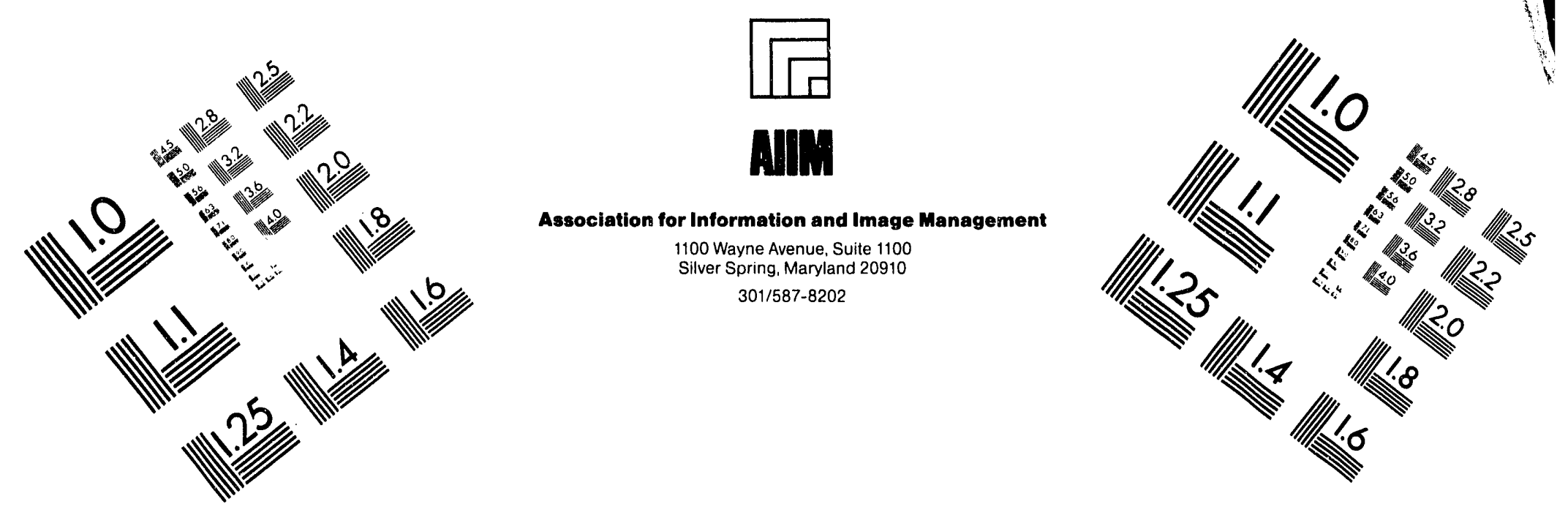

\title{
Centimeter
}

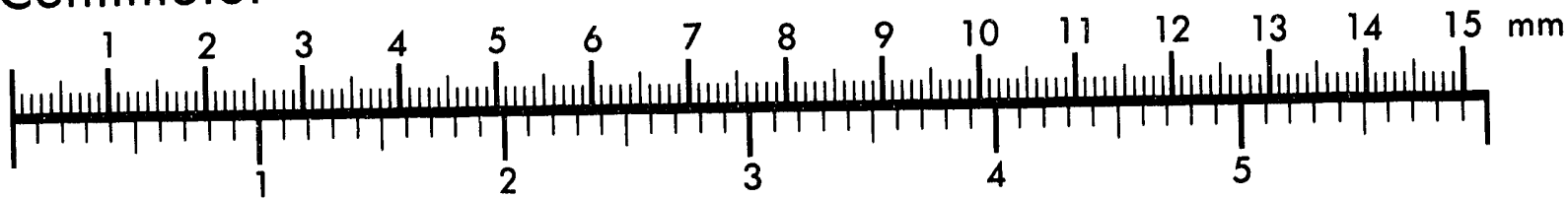
Inches
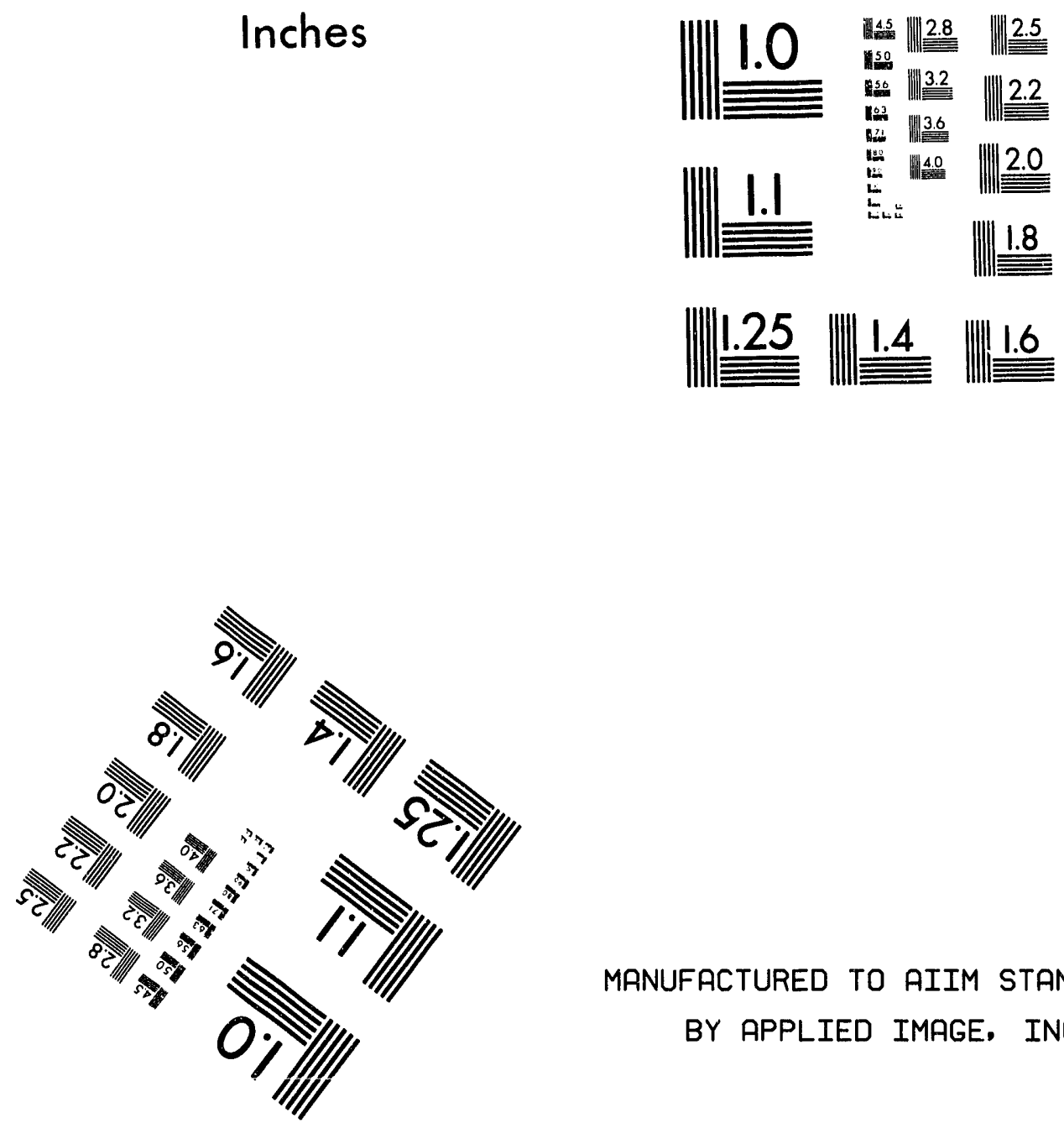

MANUFACTURED TO AIIM STANDARDS

BY APPLIED IMAGE. INC.

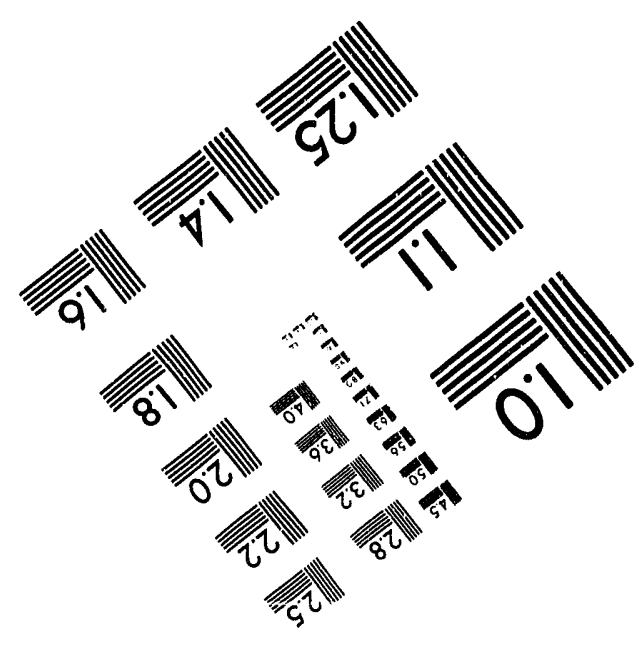



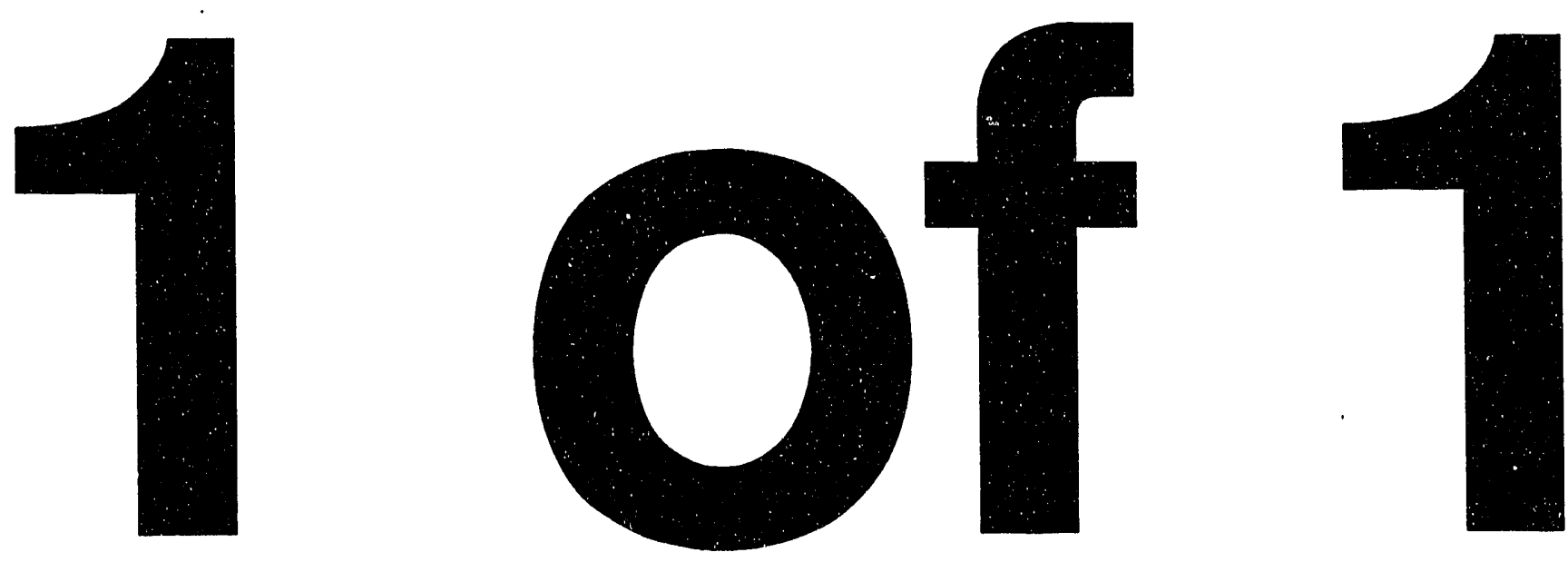


\section{Design Characteristics of the Sludge Mobilization System}

Topical Report

By
Carol L. McMahon

September 30, 1990

Work Performed Under Contract No. DE-AC07-81NE 44139

Prepared for

U.S. Department of Energy

Assistant Secretary for Nuclear Energy

Prepared by

West Valley Nuclear Services Company, Inc.

P. O. Box 191

West Valley, New York 14171-0191 


\section{Table of Contents}

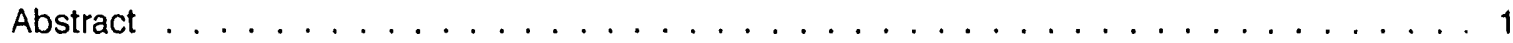

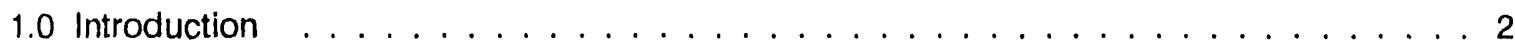

2.0 Phase 1 -Preparation of Tank Farm Area $\ldots \ldots \ldots \ldots$

3.0 Phase 11 - Sludge Washing $\ldots \ldots \ldots \ldots \ldots \ldots \ldots$

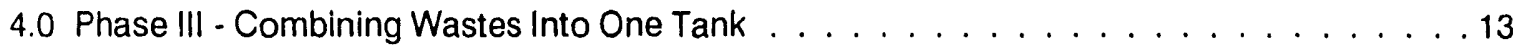

5.0 Phase IV - Resuspension and Mixing in Tank $8 \mathrm{D}-2 \ldots \ldots \ldots \ldots$

6.0 Phase V - Delivery of Slurry to the Vitrification Facility $\ldots \ldots \ldots \ldots \ldots$

7.0 Current Stage of SMS Development $\ldots \ldots \ldots \ldots \ldots \ldots$

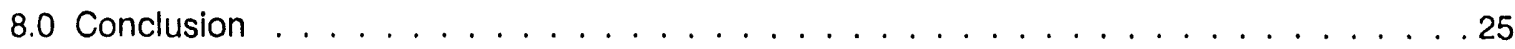

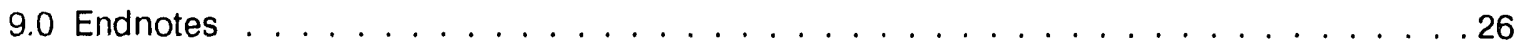

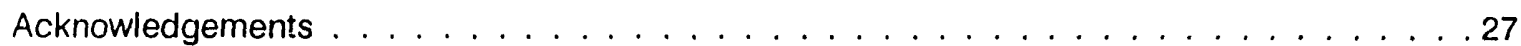




\section{Figures}

Figure $1 \quad$ Tank Farm Relation to Vitrification Facility $\ldots \ldots \ldots \ldots$

Figure 2 Sludge Mobilization Component Arrangement $\ldots \ldots \ldots \ldots$

Figure $3 \quad$ High-Level Waste Tank Contents $\ldots \ldots \ldots \ldots$

Figure 4 Tanks $8 \mathrm{D}-1$ and $8 \mathrm{D}-2$ Cut-Away $\ldots \ldots \ldots \ldots$

Figure $5 \quad$ Tanks $8 \mathrm{D}-1$ and $8 \mathrm{D}-2$ Support Trusses $\ldots \ldots \ldots \ldots$

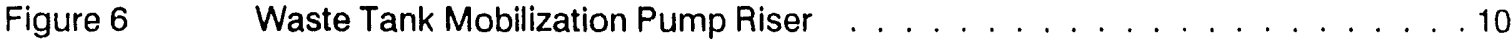

Figure $7 \quad$ Integrated Radwaste Treatment System Flow Chart $\ldots \ldots \ldots \ldots$

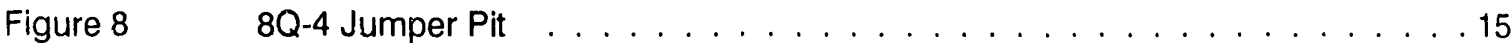

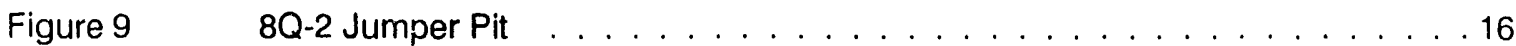

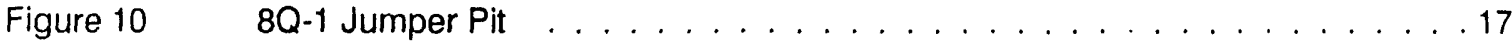

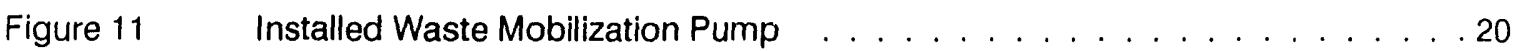

Figure $12 \quad$ Line Drawing of Waste Tanks and Trench $\ldots \ldots \ldots \ldots \ldots \ldots$

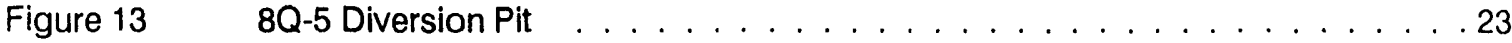




\section{Abstract}

Radioactive waste stored in underground tanks at the West Valley Demonstration Project is being processed into low-level waste and solidified in cement. High-level waste also stored underground will be vitrified and solidified into canistered glass logs. To move the waste from where it resides at the Waste Tank Farm to the Vitrification Facility requires equipment to prepare the storage tanks for low-level and high-level waste processing, equipment to mobilize and mix the radioactive sludge into a homogeneous slurry, and equipment to transfer the s!urry for vitrification. The design of the Sludge Mobilization System has incorporated the necessary components to effect the preparation and transfer of waste in five operational phases.

The first phase of the Sludge Mobilization System, which began in 1987, prepared the waste tanks to process radioactive liquid for delivery to the Cement Solidification System and to support the mobilization equipment. The second phase, beginning in 1991, will wash the sludge that remains after the liquid supernatant is decanted to prepare it for mobilization operations. The third phase will combine the contents of various waste tanks into one tank. The fourth phase will resuspend and mix the contents of the high-level waste tank. The fifth and final phase of the Sludge Mobilization System will entail transferring the waste mixture to the Vitrification Facility for processing into glass logs. Provisions for recycling the waste streams or slurries within the tank farm or for returning process streams to the Waste Tank Farm from the Vitrification Facility are also included in the final phase.

This document addresses the Sludge Mobilization System equipment design characteristics in terms of its use in each of the five operational phases listed above. 


\subsection{Introduction}

The West Valley Demonstration Project located in West Valley, New York, is the site of a former nuclear fuel reprocessing plant. From 1966 to 1972, reprocessing operations at the West Valley facility generated high-level radioactive acid Plutonium-Uranium Extraction Process (PUREX) waste (which was then neutralized), contaminated condensate, and Thorium Extraction Process (THOREX) acid waste, and stored these wastes in separate underground tanks at the West Valley site. Neutralization of the PUREX waste resulted in precipitation of some materials which formed a sludge at the bottom of the tank. When reprocessing of nuclear fuels was terminated and the facility closed, these radioactive liquids/sludge remained in the tanks for the state government to manage.

In October of 1980, the U. S. Congress passed the West Valley Demonstration Project Act which directed the Department of Energy (DOE) to safely dispose of the radioactive wastes left at the site by transforming these wastes into forms suitable for storage and transfer to a federal repository. The timely clean-up of the wastes was necessitated by the fifty-year design life of the underground tanks and by environmental concerns arising from the same issue. The liquid portion of the high-level waste tank would be purified and solidified in cement. Vitrification was selected as the method to best accomplish the transformation of the remaining highly radioactive sludge into a safely transportable, disposable product. This layer of sludge on the bottom of the high-level waste tank is comprised predominantly of settled metallic oxides. The tank farm where the wastes are stored in underground tanks and its relation to the Vitrification Facility is shown on figure 1. A flow model of the sludge mobilization components outlining the waste flow from the waste tanks to the Vitrification Facility is shown on figure 2. The task of removing the supernatant from the underground tank through eventual cement solidification is performed by the Supernatant Treatment System, Liquid Waste Treatment System, and Cement Solidification System. Removing the sludge from the highlevel waste tank and delivering it to the Vitrification Facility will be performed by the Sludge Mobilization System (SMS). Some equipment is common to the supernatant treatment for cement solidification and to sludge mobilization for vitrification. Figure 3 is a representative diagram of the contents of the high-level waste tank and disposition of both the supernatant and sludge layers.

To understand the design characteristics behind the SMS, it is necessary to comprehend the complexities presented by the original design and construction of the waste tanks. Waste tanks $8 D-1$ and $8 D-2$ are duplicate, carbon-steel tanks approximately $21.3 \mathrm{~m}$ in diameter and $8.23 \mathrm{~m}$ in height. Each tank rests in its own steel pan in individual, $0.61 \mathrm{~m}$ thick, concrete vaults. Surrounding the vaults is a layer of stiff, silty clay having low permeability. Prior to Supernatant Treatment System operations, Tank 8D-2 contained approximately $2,420 \mathrm{~m}^{3}$ of neutralized PUREX waste, $170 \mathrm{~m}^{3}$ of that being sludge. During supernatant processing, approximately one-third of the $8 \mathrm{D}-1$ tank was filled with slightly contaminated water. 
This water cools and shields a layer of Zeolite loaded with cesium 137 which was added to the tank as a by-product of supernatant processing.

Girders and rafters stiffen and strengthen the roof of both high-level waste tanks. Supporting the girders of each tank are forty-five $200 \mathrm{~mm}$ diameter pipe columns. On the bottom of these pipe columns is a complex array of support girders held in place by a series of plates and stay bolts. The six concrete vault roofsupport columns are inside $1.2 \mathrm{~m}$ diameter carbon-steel sleeves or access risers. Figure 4 details the internal gridwork of the $8 \mathrm{D}-1$ and $8 \mathrm{D}-2$ tanks. The sludge layer has settled within the bottom gridwork of the $8 \mathrm{D}-2$ tank. The internal structure of these tanks as well as the safe transfer of the high-level waste has guided the design of the SMS.

Tanks 8D-3 and 8D-4 are also duplicates. They are made of stainless-steel and are approximately $3.7 \mathrm{~m}$ in diameter and $4.8 \mathrm{~m}$ in height. These tanks reside underground in a common reinforced concrete vault lined to a height of $0.5 \mathrm{~m}$ with stainless-steel. Tank $8 \mathrm{D}-4$ contains approximately $35 \mathrm{~m}^{3}$ of THOREX nitric acid waste. The 8D-3 tank was originally used only as a spare. It is currently used as an integral part of supernatant processing.

This document focuses on the design characteristics of the SMS equipment as they relate to the transfer and mobilization of high-level radioactive waste. Preparation of the waste tanks and supernatant processing is included as background to sludge mixing and delivery to the Vitrification Facility. Components of the system are defined and their purpose explained in relation to the vitrification process.

The design of the SMS is complete. Construction of the waste transfer system began early in 1990 . 


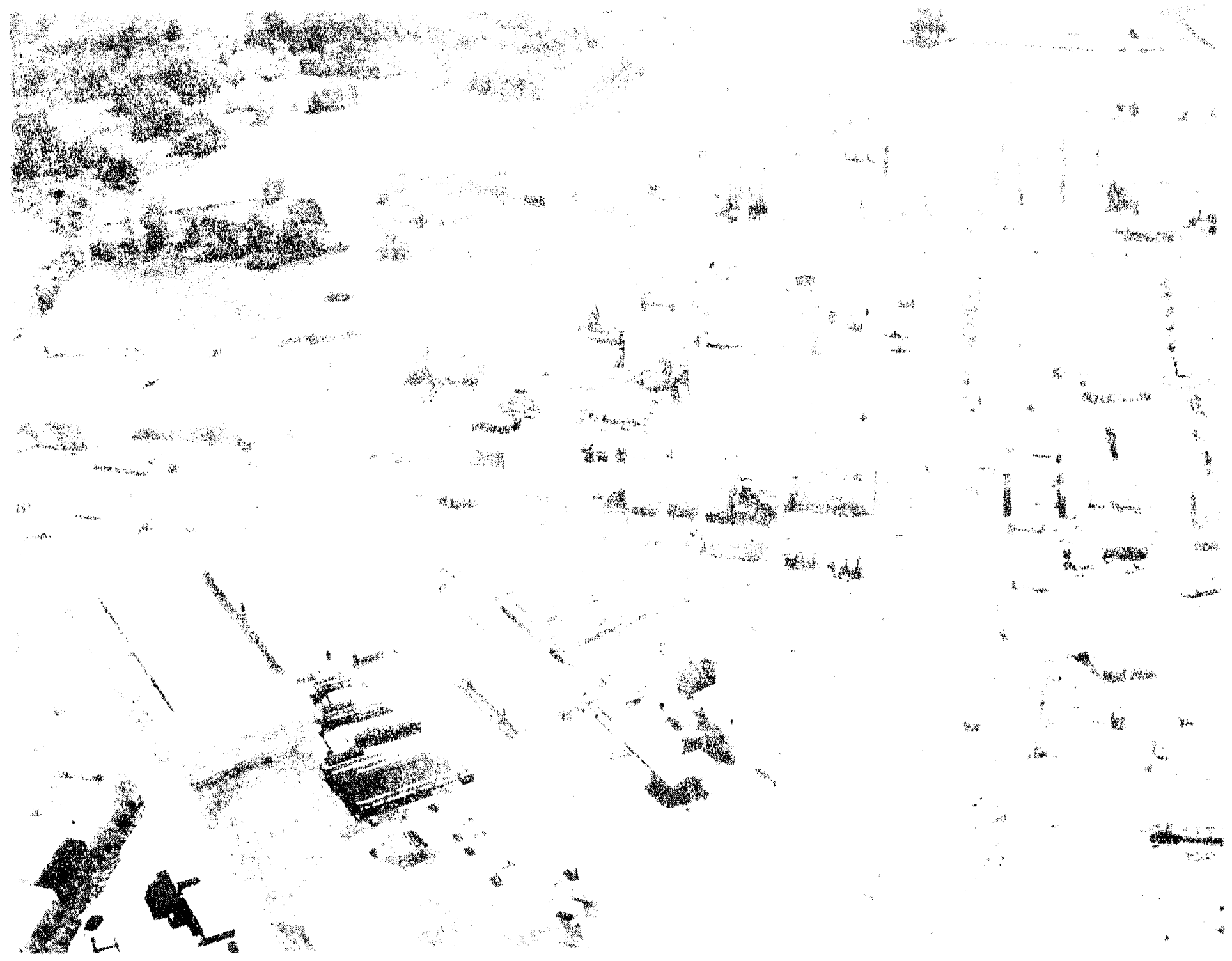

Figure 1

Cut-Away of the Vitrification Facility 


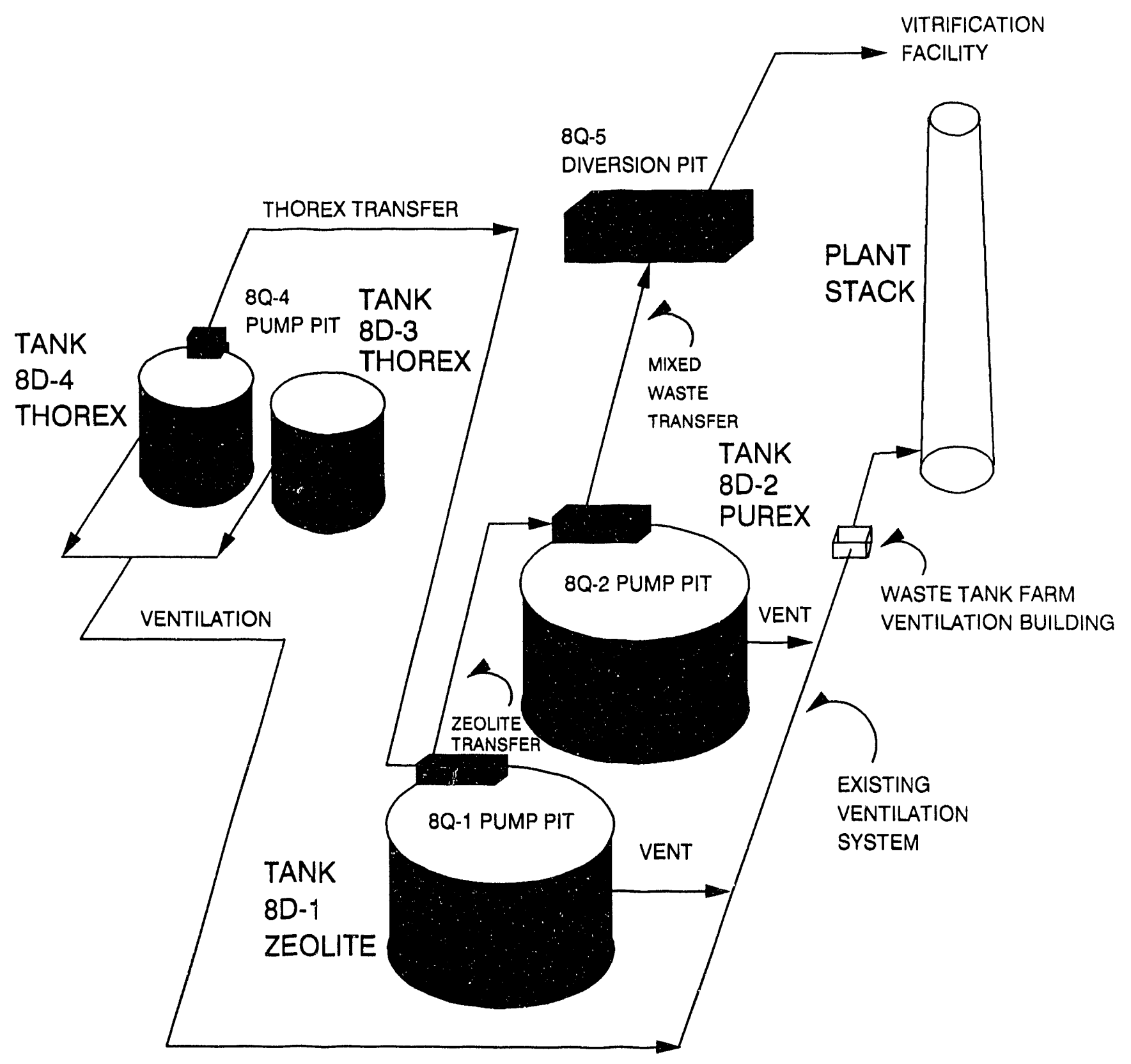

Figure 2

Sludge Mobilization Component Arrangement 


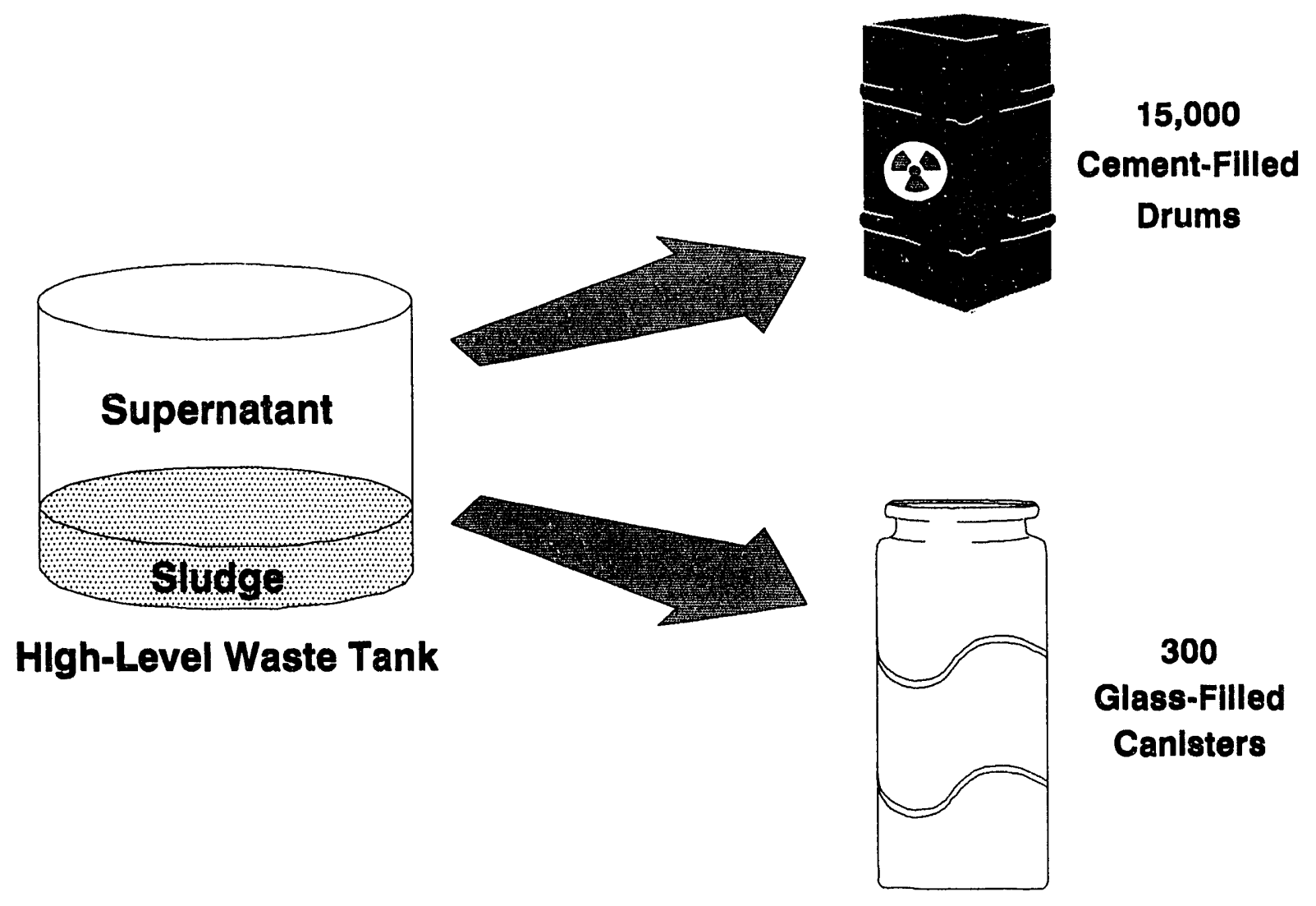

Figure 3

High-Level Waste Tank Contents 


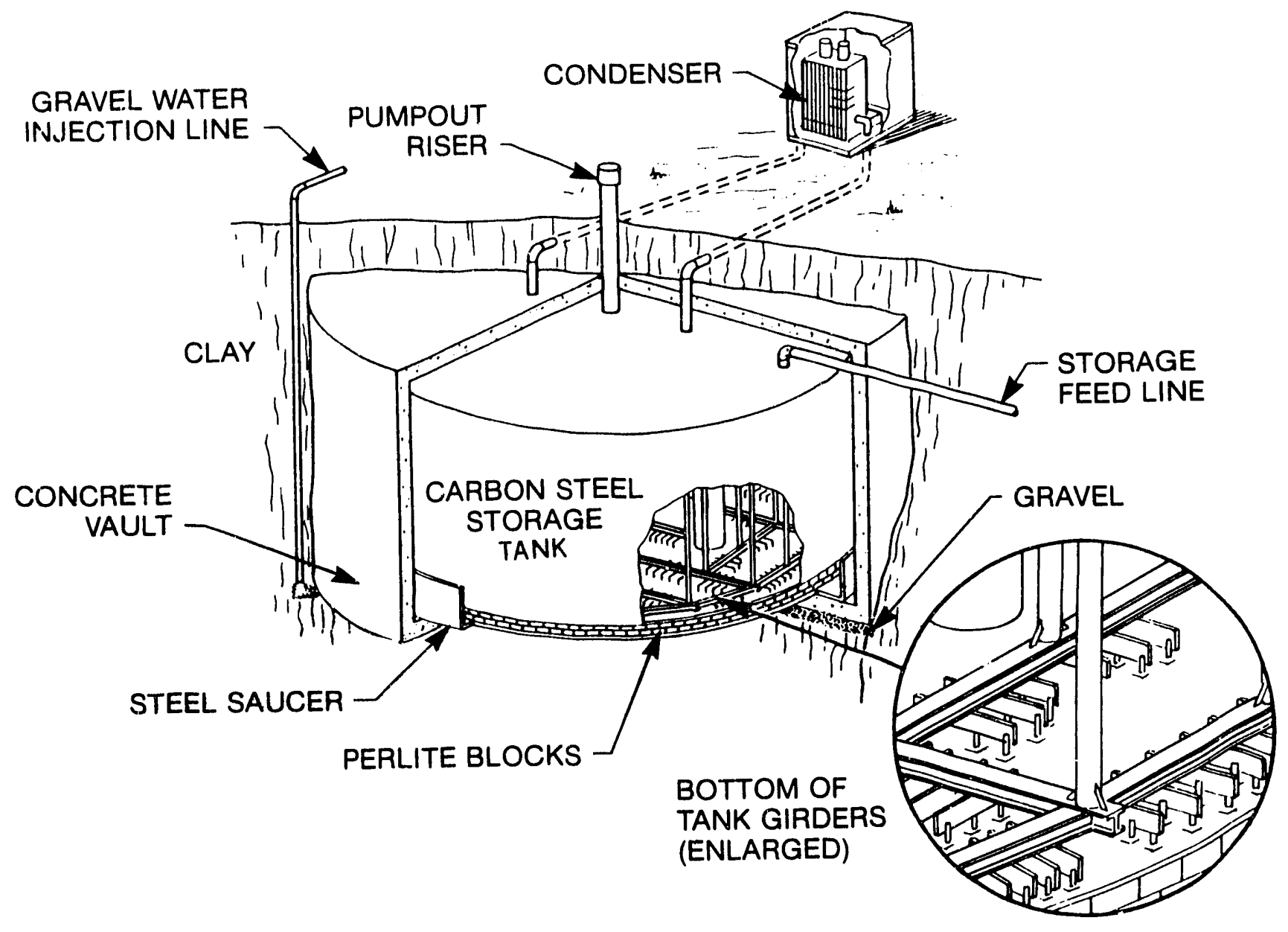

Figure 4

Tanks 8D-1 and 8D-2 Cut-Away 


\subsection{Phase I - Preparation of Tank Farm Area}

Since the 8D-1 and 8D-2 tank vaults were not designed for large equipment loads, supporting trusses spanning the two tanks had to be constructed. These supporting structures were designed to carry both static and seismic loads of the mobilization equipment (mixing pumps) away from each tank vault. Figure 5 is a schematic of the support trusses over Tanks $8 D-1$ and $8 D-2$. To complete the tank confinement barriers between the tank access risers (pipe penetrations) and support structures, a flexible expansion bellows was used. This type of connection does not structurally tie the risers to the supporting trusses and allows the structure to move freely without impacting loads to the risers and therefore the tank vaults.

Access risers in the waste tanks permit the insertion of transfer and mobilization pumps as well as other sampling or monitoring equipment. These risers extend from approximately $5 \mathrm{~m}$ above the tank top down through the vault roof and are attached to the tank lid. ${ }^{1}$ A schematic of a waste tank mobilization pump riser is shown on figure 6. 


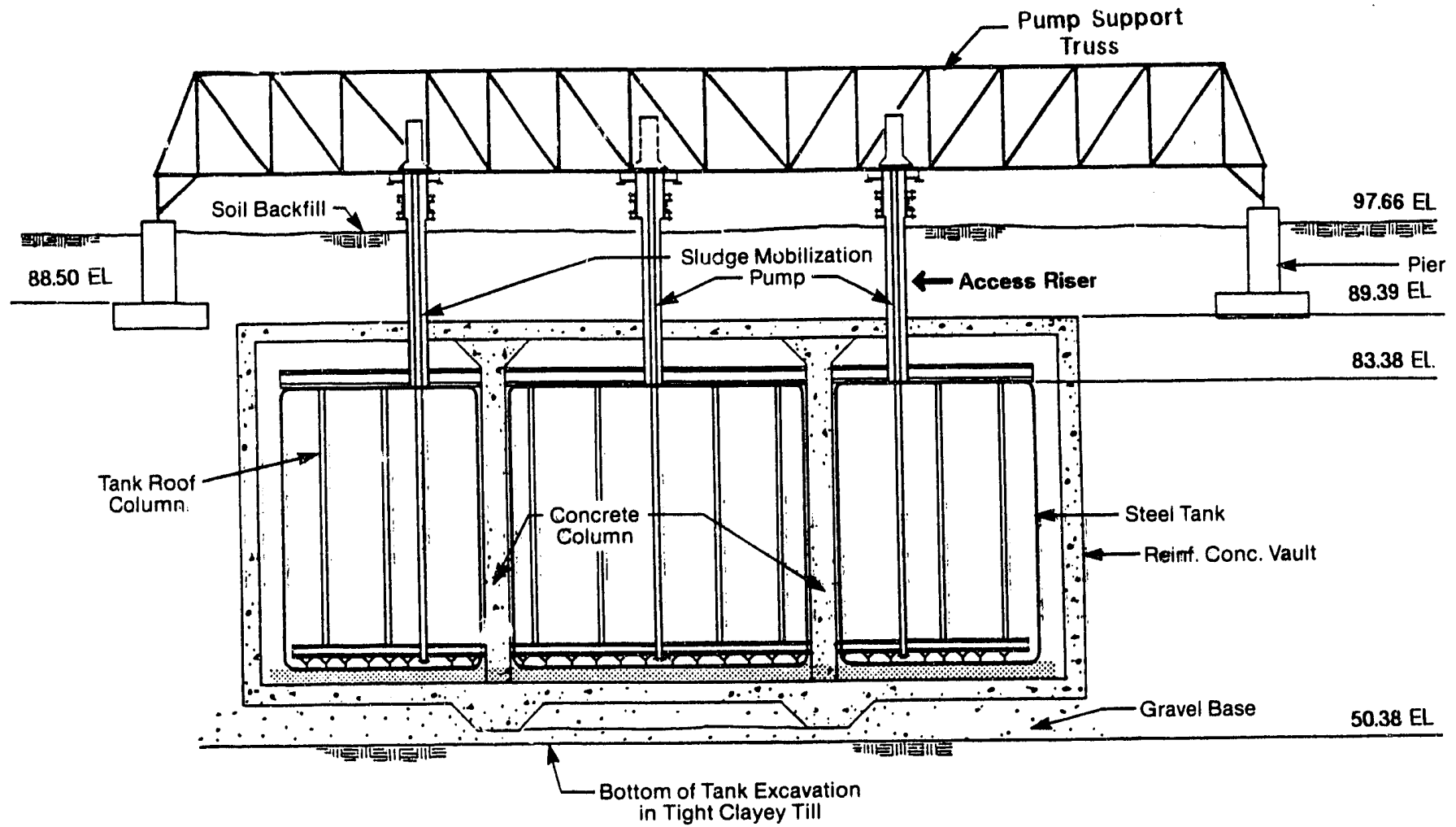

Figure 5

Tanks 8D-1 and 8D-2 Support Trusses 


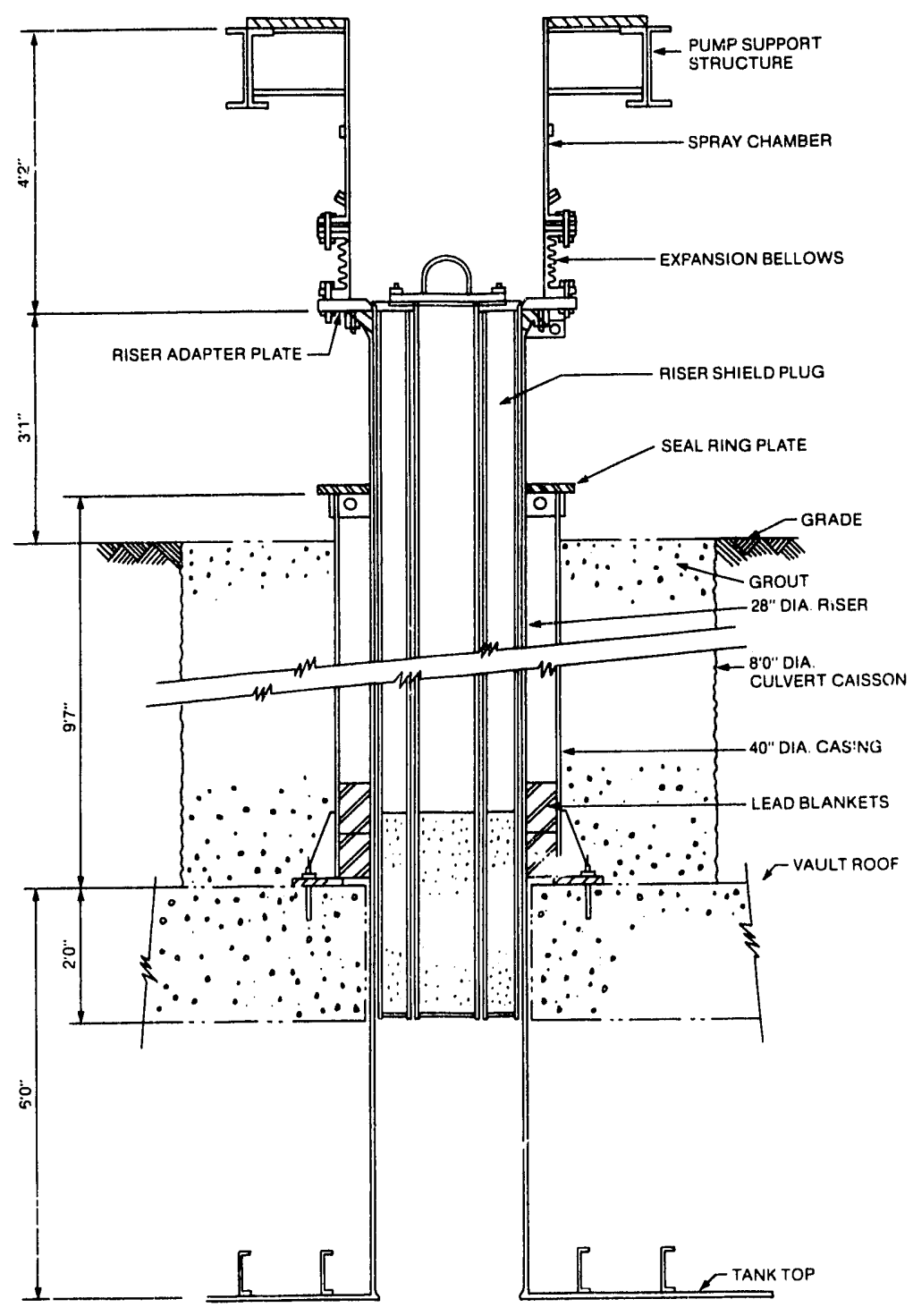

Figure 6

Waste Tank Mobilization Pump Riser 


\subsection{Phase II - Sludge Washing}

The neutralized PUREX waste stored in Tank 8D-2 has physically separated into a liquid salt solution (supernatant) above a semi-solid sludge. This high-level waste is being processed by decanting the supernatant and removing the cesium through the lon exchange columns located in Tank 8D-1 as shown on the IRTS processing overview, figure 7. The resulting decontaminated supernatant is solidified in cement and stored as low-level Class $C$ radioactive waste. The primary objective of rernovil $y$ the supernatant from the $8 \mathrm{D}-2$ tank is to reduce the volume of high-level waste that will be fed to the Vitrification Facility and ultimateIy solidified into a borosilicate glass product. Some of the major components of the SMS are in place and are currently being used in conjunction with the Supernatant Treatment Systzm, Liquid Waste Treatment System, and Cement Solidification Systems for treatment and processing of the supernatant in the 8D-2

tank. ${ }^{2}$ When the removal of the supernatant from storage Tank 8D-2 has been completed, the remaining sludge will be washed using process water to remove both supernatant salts and salt crystals. The wash water will then be processed using the existing Liquid Waste Treatment System (LWTS) and Cement Solidification System (CSS) processing systems. Once the PUREX sludge is washed of its salts, a quantity of sodium hydroxide will be added to the $8 \mathrm{D}-2$ tank in preparation for pumping the THOREX waste from Tank 8D-4 to Tank 8D-2. The sodium hydroxide will precipitate the thorium metal ions and neutralize the nitric acid of the incoming liquid. 


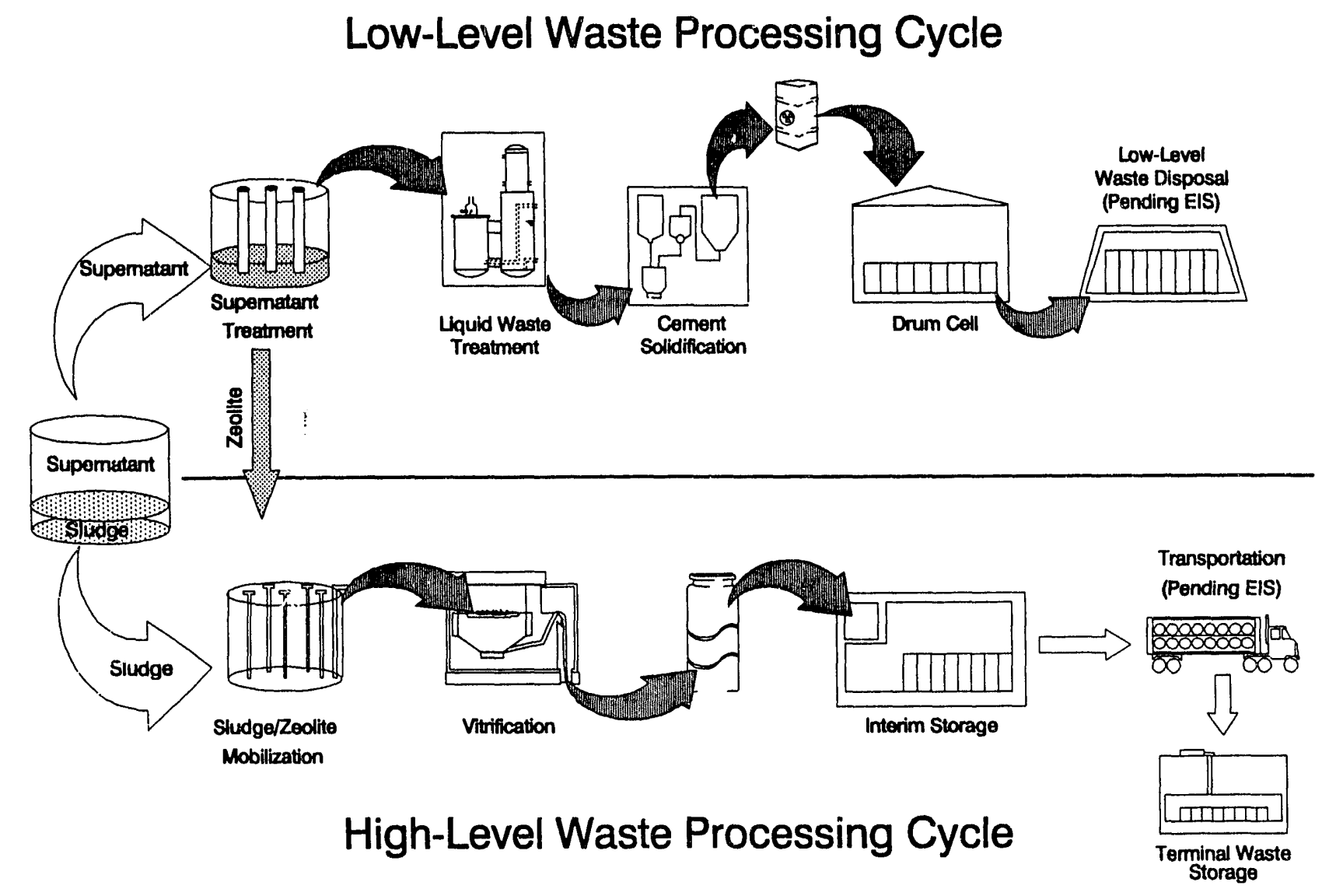

Figure 7

IRTS Process Flow Chart 


\subsection{Phase III - Combining Wastes Into One Tank}

Since the THOREX in Tank 8D-4 is a liquid, it will require removal and not mobilization. Each waste tank has an associated pump pit iocated above the tank structure. After modifying the tank's existing riser, a single long-shafted removal pump will be installed. The THOREX waste will be pumped out of the tank and through the $8 \mathrm{Q}-4$ pump pit as seen in figure 8 . The $8 \mathrm{Q}-4$ pit above the $8 \mathrm{D}-4$ tank vault is a $.61 \mathrm{~m}$ thick, stainless-steel lined, reinforced concrete structure. Its interior dimensions are $1.83 \mathrm{~m}$ wide by $2.13 \mathrm{~m}$ long. As is true with all of the pits, one of the $8 Q-4$ pit's purposes is to provide radiation shielding adequate for controlled access. Each of the pits must also be self-contained and accessible to remote maintenance by an overhead gantry and/or jib crane. There is an average vertical working space within the pits of approximately $2 \mathrm{~m}$. Due to the environment in the pits, any equipment having the potential to fail will be required to be serviced or replaced by remote means. All transfer piping connections to process equipment (valves, pumps) will be performed with remotely cc upled jumpers using PUREX-type connectors.

Jumpers contain instrumentation to operate and monitor the transfer operations. Jumper instrumentation includes flow meters, thermocouples, pressure indicators, and limit switches to indicate valve open or closed positions. Instrument failure will be remedied by remotely replacing the entire jumper. The pump discharge will be via a process line jumper to piping which egresses through the pit wall. For added safety, each pit floor is sloped to a low-point drain where contaminated liquids will be collected before being discharged into their respective tank.

The THOREX will be pumped through the pit jumpers into double-walled stainless-steel piping which is contained inside a concrete trench that leads to the $8 \mathrm{Q}-2$ jumper pit as shown on figure 9 and assembly above the 8D-2 high-level waste tank vault.

The contents of Tank 8D-1, spent Zeolite and radioactively-contaminated process water will first require mobilization to resuspend settled solid particles. Tank 8D-1 has eight access risers or pipe penetrations five of which will be used to house mobilization pumps and one will house a removal pump. The remaining two risers are capped with shield plugs and are intended to be used as spares. Similar to the arrangement in the $8 \mathrm{Q}-4$ jumper pit, the $8 \mathrm{Q}-1$ jumper pit, as shown on figure 10 , is a $3.35 \mathrm{~m}$ wide by $4.11 \mathrm{~m}$ long (interior dimensions), $.61 \mathrm{~m}$ thick concrete box. It is also lined with stainless-steel and the pit floor sloped to a drain for collection of contaminated liquids before their return to the tank. Figure 10 is a computergenerated drawing of the $8 Q-1$ jumper pit.

The slurry (mixed Zeolite and water) is pumped through the jumpers in the $8 Q-1$ pit, regulated by a variable speed motor control and monitored with the jumper instrumentation. Slurry is transferred from the pit via double-walled stainless-steel pipe contained in a shielded concrete trench to the $8 Q-2$ jumper pit and 8D-2 high-level waste tank. 
The 8Q-2 jumper pit is located on top of the 8D-2 high-level waste tank vault. The pit's interior dimensions are $3.66 \mathrm{~m}$ long by $4.11 \mathrm{~m}$ wide, it is lined with stainless-steel, and has $0.61 \mathrm{~m}$ thick concrete walls. Refer to figure 9 for an isometric view of the $8 Q-2$ jumper pit. Inside of the $8 Q-2$ pit, an in-line grinder will be used to reduce the size of the Zeolite particles transferred from Tank 8D-1. The grinder assembly will consist of a 40 -horsepower motor that drives a single shaft with three rotary blades which are capable of grinding the Zeolite particles to less than 50 microns. It is anticipated that, at $3,600 \mathrm{rpm}$, the grinder will be able to process approximately $70 \mathrm{gpm}$ of slurry. Once the slurry passes through the grinder, it is deposited in the 8D-2 high-level waste storage tank and mixed with the washed PUREX sludge and neutralized THOREX. 


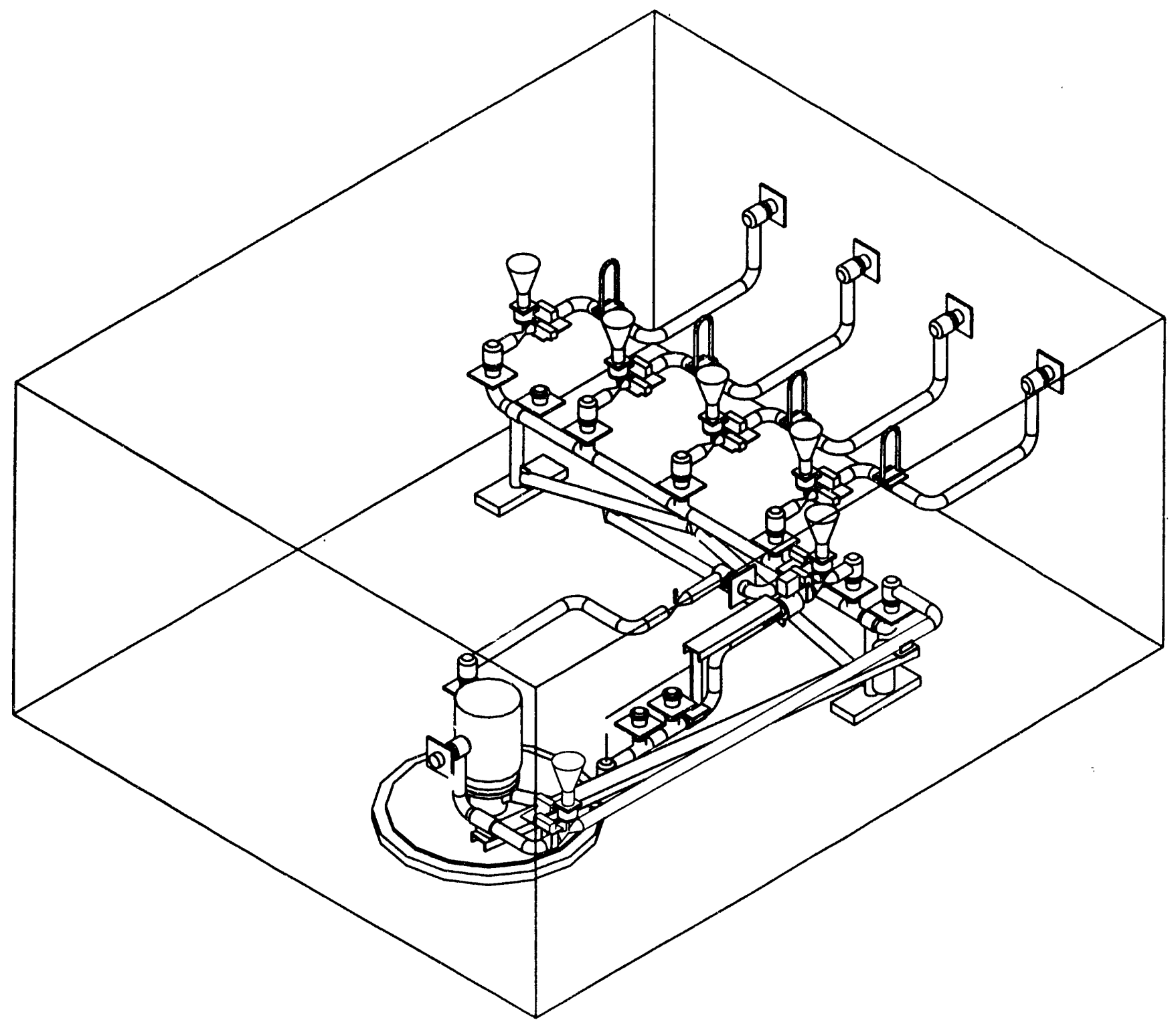

Figure 8

8Q-4 Jumper Pit 


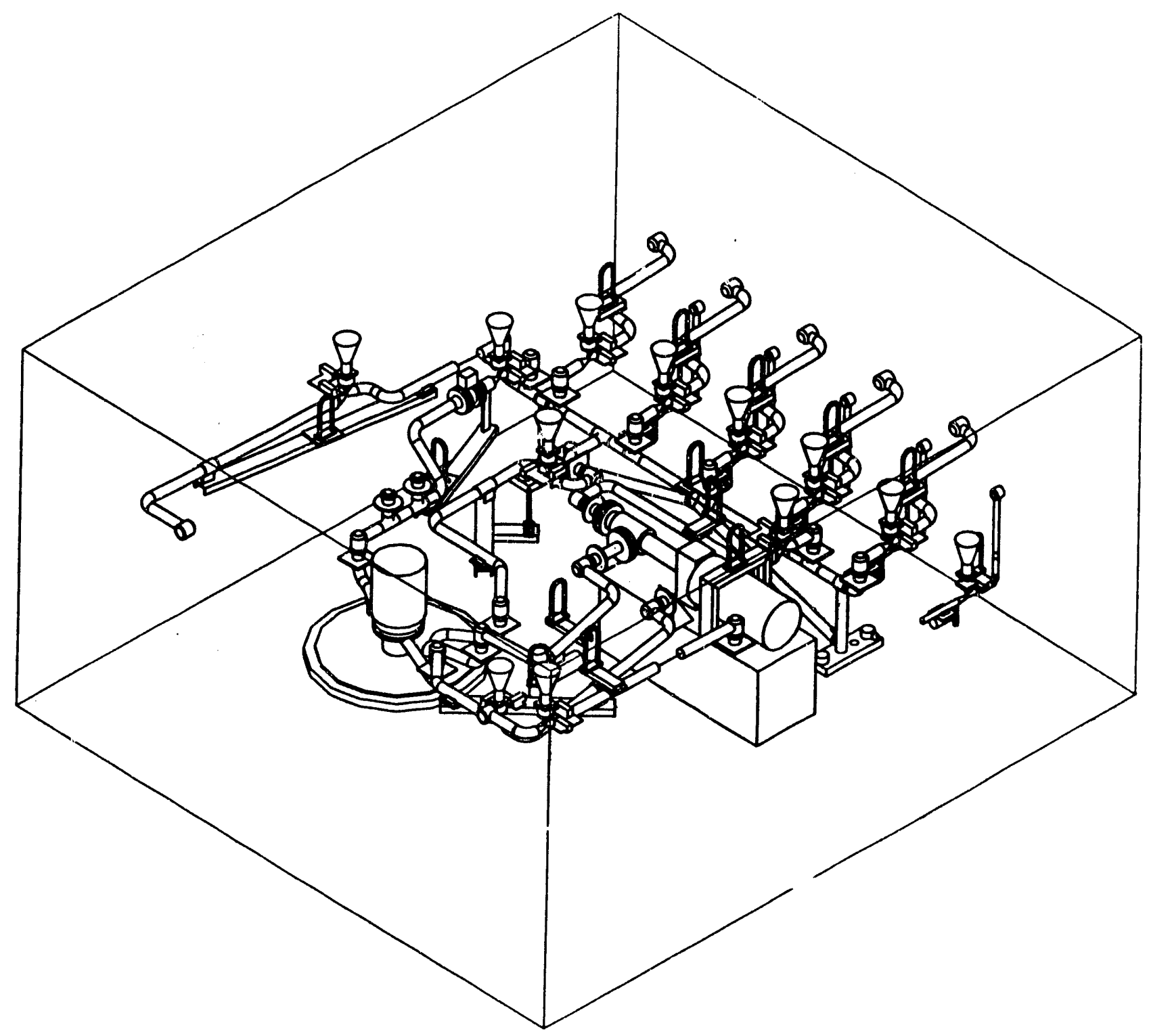

Figure 9 8Q-2 Jumper Pit

16 


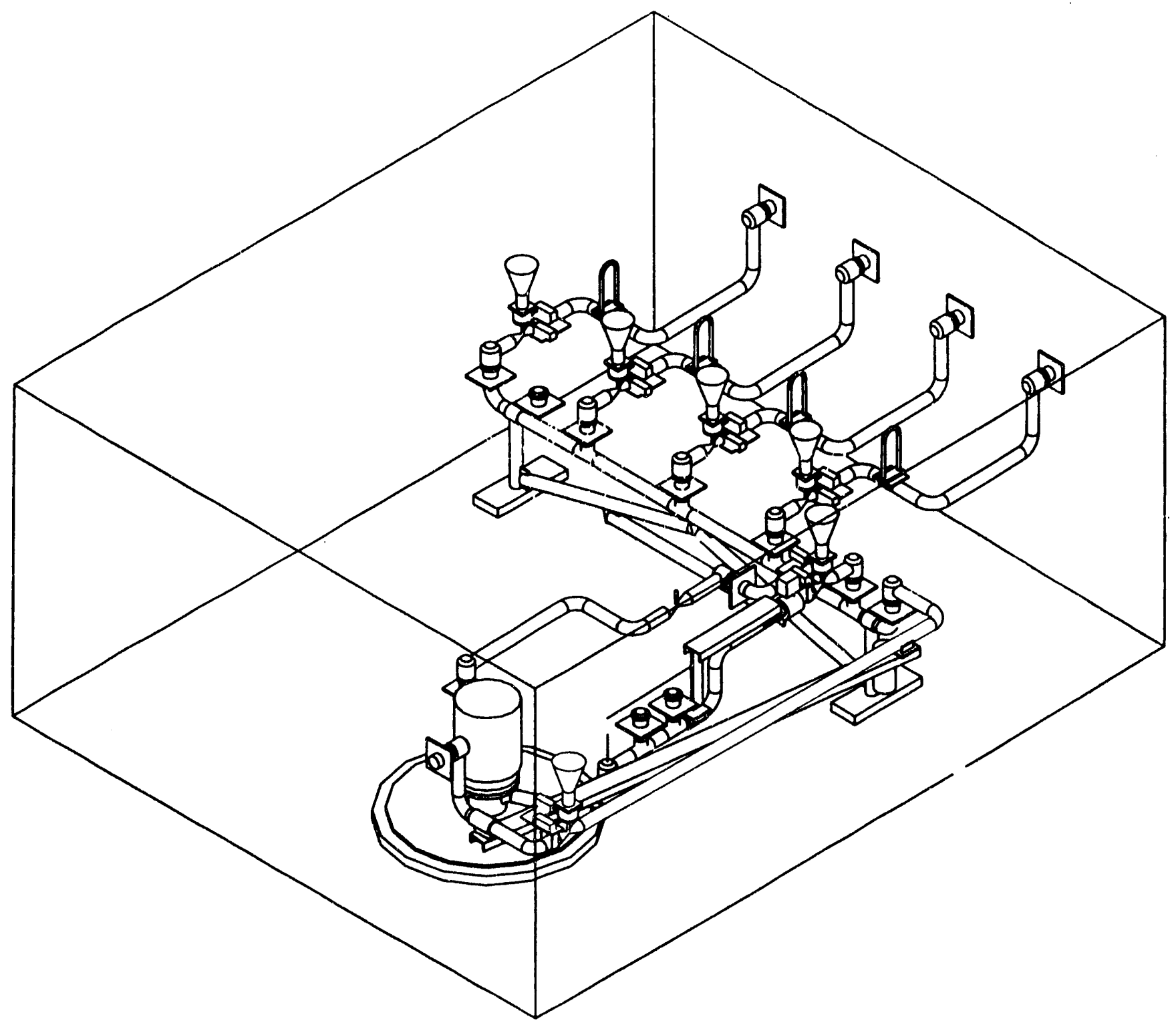

Figure 10

8Q-1 Jumper Pit 


\subsection{Phase IV - Resuspension and Mixing in Tank 8D-2}

After the 8D-2 high-1 vel waste tank has received the wastes transferred from Tanks $8 D-4$ and $8 D-1$, the contents will be blended to form a homogeneous slurry. The advantage of combining the waste streams before transfer to the Vitrification Facility is that a single feed stream allows development of a single glass recipe rather than separate recipes for each of three separate streams of vastly different compositions.

There are nine access risers in Tank 8D-2. Only one riser was installed when the tank was originally constructed. The other eight risers were installed using remote equipment and techniques. Locations for the additional risers were selected after performing reduced-scale modeling. For sludge mobilization, five risers will contain mobilization pumps, one will support a removal pump. As in Tank 8D-1, the remaining risers have shield plugs. The mobilization pumps will mix the PUREX, THOREX, and spent Zeolite wastes while the removal pump is operating. These pumps which resuspend the settled solids are the same ones used to dissolve the salt crystals and displace the supernatant salts during sludge washing.

A low-pressure, high flow, in-tank recirculation technique for mobilizing the PUREX sludge was developed through scale-model testing. This technique uses a low-pressure slurrying system to immerse the pump in the sludge layer so that a recirculating mixture of sludge and liquid will serve as feed to the pump. One important aspect of this technique is that the waste does not leave the tank confinement barrier for the purpose of agitation.

Deep-well long-shafted centrifugal pumps used in the agriculture industry were selected as the basis of the mobilization pump design. These pumps operate with a given flow rate through two opposing nozzles while rotating on a turntable at 0.2 to $0.5 \mathrm{rpm}$ providing $360^{\circ}$ coverage. Mobilization pumps are approximately $15.24 \mathrm{~m}$ in length from the bottom of the mounting flange to the pump bottom with two 38.1 $\mathrm{mm}$ diameter discharge nozzles. Scale testing has shown that a total of five pumps, each having a 150 horsepower motor and an operating range of 600-2,000 rpm using a variable frequency motor speed control and minimum capacity of $1,200 \mathrm{gpm}$, will be sufficient to churn the settled solids into a transportable slurry. These pumps have been designed to discharge beneath the complex bottom gridwork of the tank and to use the mobilized sludge to scour the tank bottom and internal structure. A waste mobilization pump as it will be installed within an access riser is shown on figure 11. A separate long-shafted centrifugal pump, very similar in design to the mobilization pumps, will be used for removal of the slurry from the 8D-2 tank. These removal pumps will also be variable speed controlled and capable of managing the expected wide range of solids concentration during the waste transfer operations. The flow rate of the transferred slurry will vary depending on the amount of solids concentration to prevent the solids from settling in the transfer lines. The variable speed control also eliminates the need for a flow control valve. 
The simultaneous operation of the mobilization and removal pumps will ensure that the liquids and solids do not separate before transfer.

The combined waste stream will exit the 8D-2 tank and enter the 8Q-2 jumper pit. At this point, valving in the jumpers cail direct the steam back through the grinder to reduce particle size or into the double-walled piping within the concrete trenching for delivery to the Vitrification Facility. Note that the contents of the high-level waste tank, if directed out of the tank and into the grinder, will be recycled back into the same tank for further mixing by the mobilization pumps. 


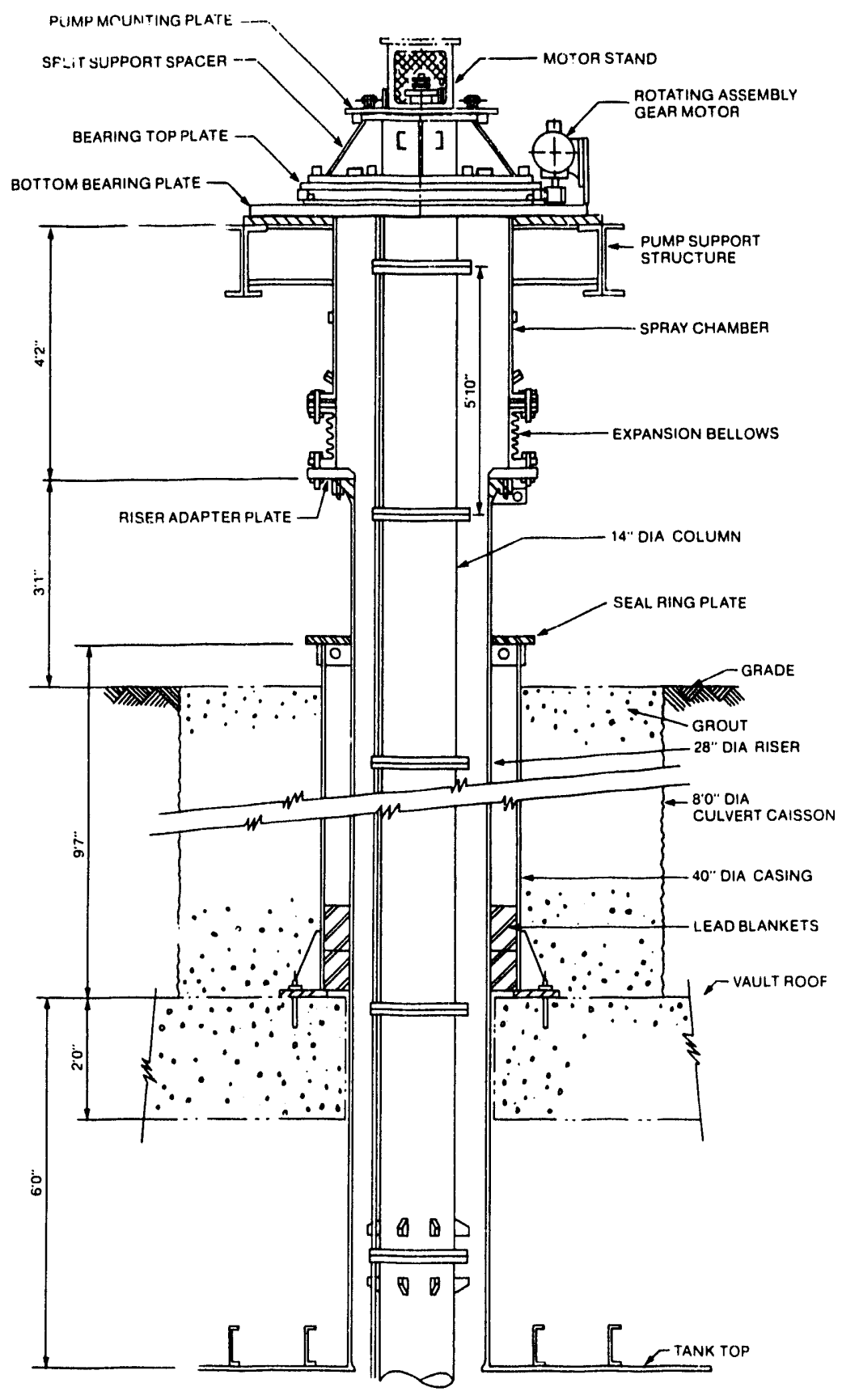

Figure 11

Installed Waste Mobilization Pump 


\subsection{Phase V - Delivery of Slurry to the Vitrification Facility}

After a batch of slurry (approx. 17,000 liters) is transferred out of the 8Q-2 jumper pit, it will be carried through the $8 Q-5$ diversion pit to the Vitrification Facility by double-walled stainless-steel piping within a concrete trench. This concrete shielded trench from the $8 \mathrm{D}-2$ tank to the Vitrification Facility is roughly $100 \mathrm{~m}$ in length with an average height and width of $1.83 \mathrm{~m}$ and thickness of $0.61 \mathrm{~m}$. The top of the trench is at grade level. Its concrete lid is sectioned to provide remote removal capabilities once the waste processing campaign is complete. Figure 12 outlines the trench from the $8 D-1 / 8 D-2$ tanks to the Vitrification Facility.

The 8Q-5 diversion pit regulates all slurry, service, and chemical lines going both to and from the Vitrification Facility. Jumpers running through the pit house valving containing limit switches and leak detection equipment; a schematic is shown on figure 13. The $8 Q-5$ diversion pit interior dimensions are $3.66 \mathrm{~m}$ wide by $3.0 \mathrm{~m}$ long, with $.61 \mathrm{~m}$ thick concrete walls. The pit walls and floor are lined with stainless-steel and the floor is sloped to drain any escaping radioactive liquids back to the 8D-2 tank. Provisions to flush the piping with water after each batch transfer of slurry or return of waste from the Vitrification Facility have been incorporated into the SMS design. Back-flushing of the lines will recycle contamination to the 8D-2 tank.

When the slurry exits the $8 Q-5$ pit, it is again piped through the trench through double-walled stainlesssteel lines to the make-up tank where process water will be evaporated and the sludge concentrated before vitrification. 


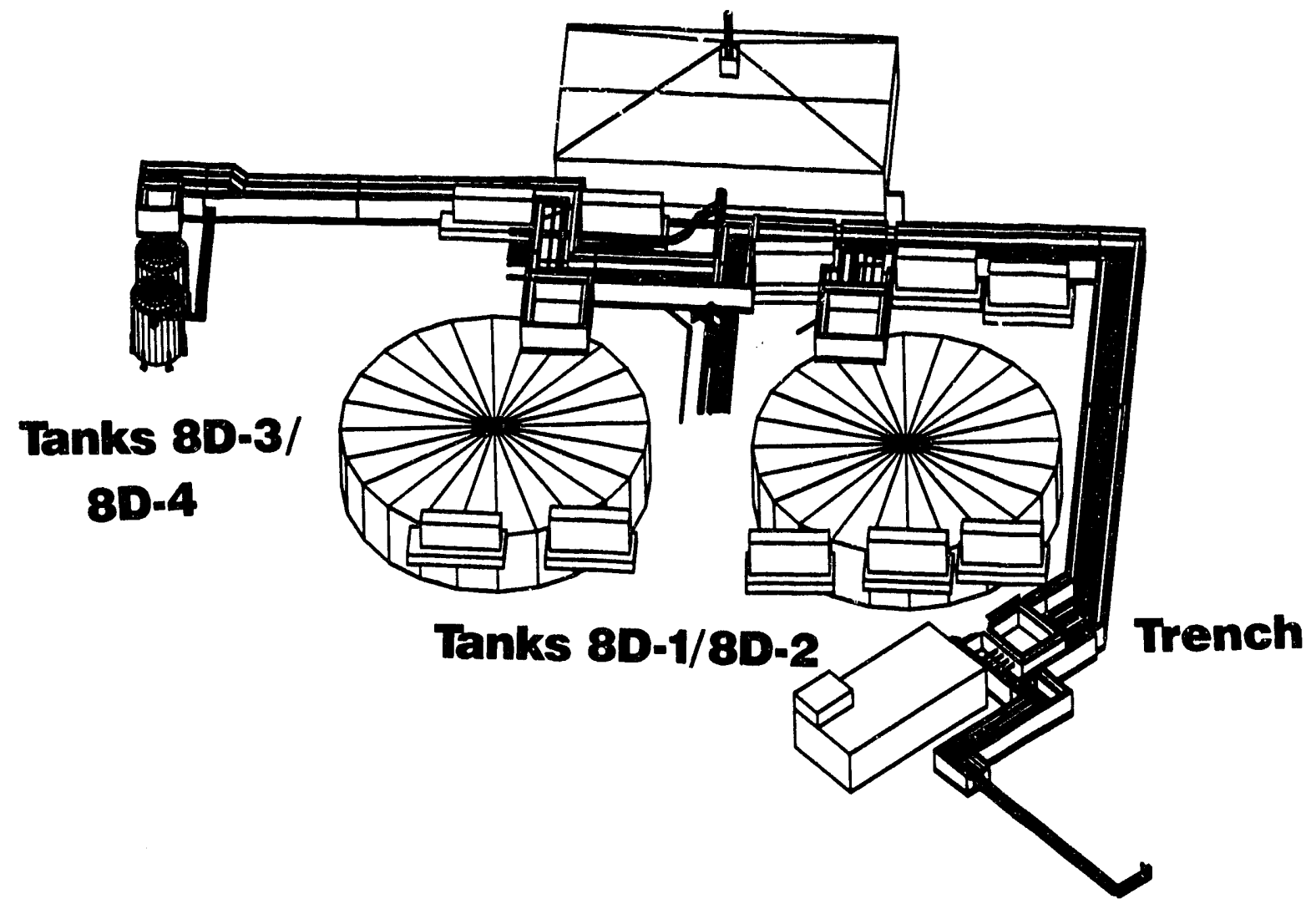

Figure 12

Line Drawing of Waste Tanks and Trench 


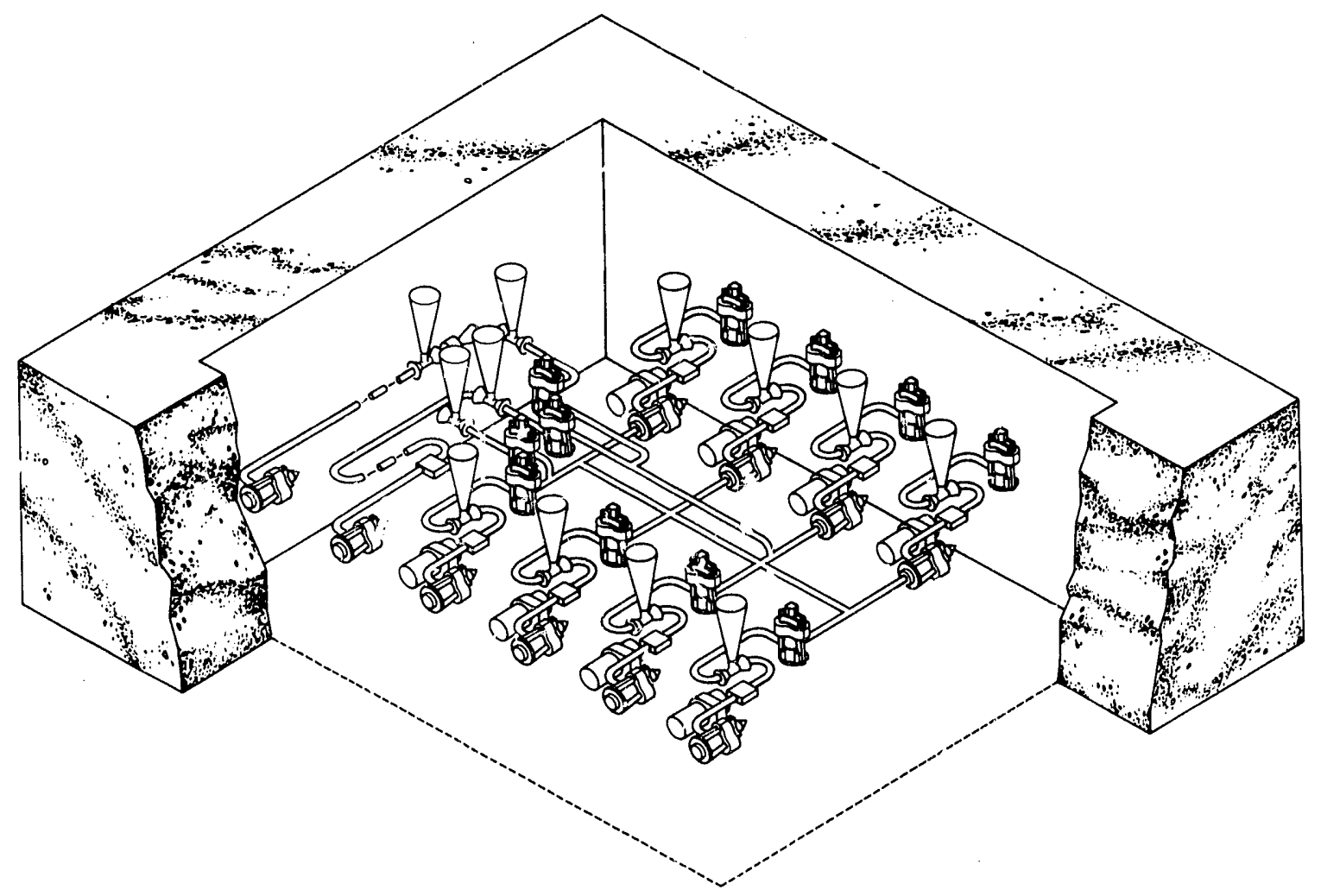

Figure 13

8Q-5 Diversion Pit 


\subsection{Current Stage of SMS Development}

System components to accomplish the removal, mixing and transfer operations of the SMS have all been designed. Mobilization pumps have been procured and are scheduled to be installed inside the existing tank risers in Tanks 8D-1 and 8D-2 during the spring of 1991. Excavation work has begun for the concrete pits and the pipe trench for transferring the radioactive waste stream from the high-level waste tank to the Vitrification Facility. Fabrication of the pit jumpers and jumper instrumentation is scheduled to begin in 1991. Project schedules set the first high-level waste Tank 8D-2 sludge wash to start in 1991. Batch transfer of the homogeneous radioactive waste slurry to the concentrator feed make-up tank in the Vitrification Facility is scheduled to begin in 1994. 


\subsection{Conclusion}

The first operational phase of the SMS as defined in this paper is nearing completion. The second phase, sludge washing, is scheduled to begin in 1991. Modifications to the preliminary design as a result of scale testing have been included in the SMS final design. Design attributes of the SMS also include multiple radiation confinement barriers for protection of West Valley Demonstration Project personnel and the general public. These barriers are designed to maintain their integrity following design basis seismic events.

The SMS design incorporates the components and features to safely and effectively transfer the highly radioactive material from its present location to the Vitrification Facility. 


\subsection{Endnotes}

1) Information on the installation of risers in high radiation waste tanks at the West Valley Demonstration Projects is presented in topical report "Remote Installation of Risers on Underground Nuclear Waste Storage Tanks": J. P. Jackson and R. F. Gessner, 1988, DOE/NE/44139-45.

2) Low-level waste treatment and solidification information can be located in topical reports "Low-Level Waste Cement Solidification Design, Installation, and Start-Up", G. R. Jezek, 1988, DOE/NE/44139-50 and "Design and Construction of the Low-Level Liquid Waste Treatment System", M. N. Baker, W. E. Mateer, et. al., 1989, DOE/NE/44139-56. 


\section{Ackriowledgements}

The authors wish to acknowledge the following individuals for their contributions to this report:
P. Bednarz
R. R. Borisch
D. C. Burns
R. W. Devlin
R. W. Martin
C. J. Pruitt
M. A. Schiffhauer 

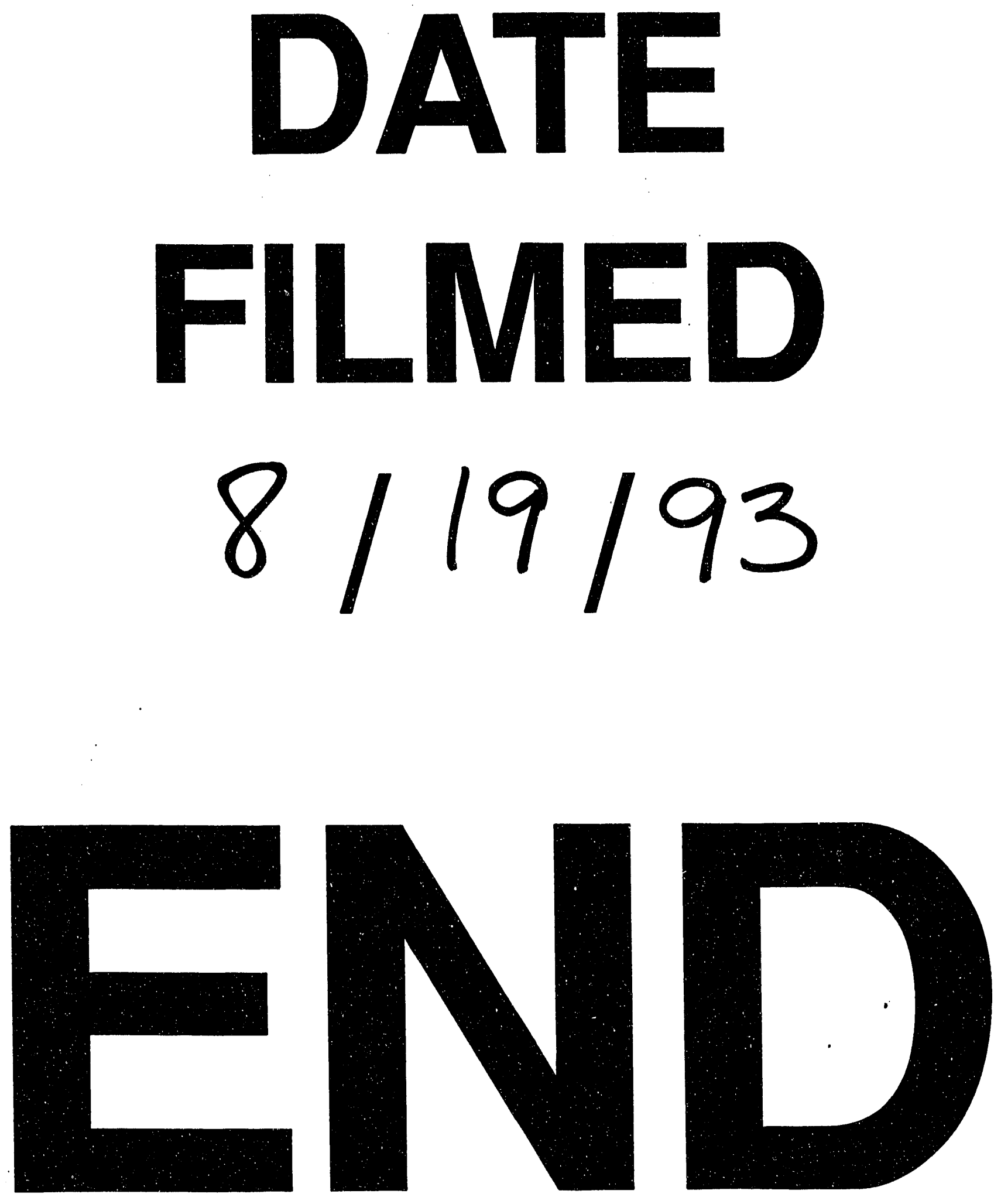
